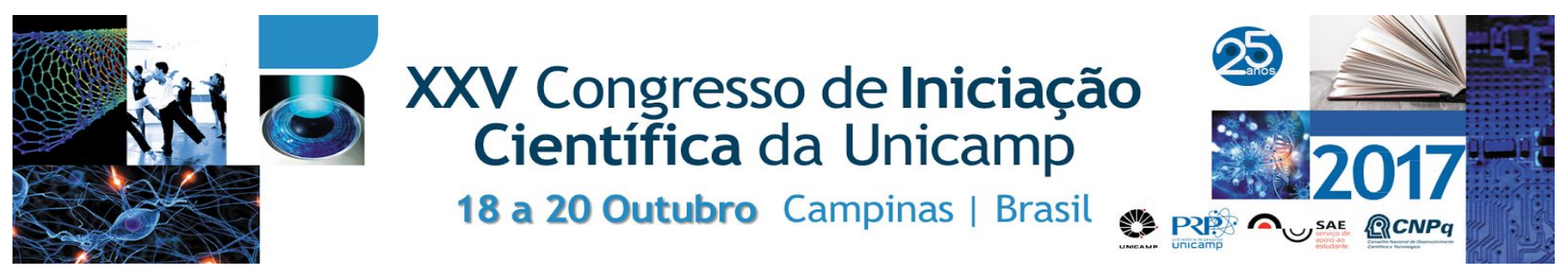

\title{
Análise de partidos arquitetônicos na arquitetura residencial do Eduardo de Almeida
}

\author{
Vinicius M. Rossi ${ }^{*}$, Ana Maria Tagliari Florio - orientadora
}

\section{Resumo}

A pesquisa tem como objetivo a investigação do partido de quatro projetos residenciais projetados por Eduardo de Almeida na cidade de São Paulo, entre as décadas de 1970 e 90. Por meio de desenhos e diagramas pretende-se compreender como o arquiteto organizou o programa de necessidades, a circulação, sistema estrutural e a implantação. Assim, buscando a compreensão da arquitetura contemporânea de Almeida através dessas análises de projetos residenciais.

\section{Palavras-chave: \\ Eduardo de Almeida, partido arquitetônico, análise gráfica por diagramas}

\section{Introdução}

Esta pesquisa tem como objeto de investigação quatro projetos residenciais desenhados pelo arquiteto Eduardo de Almeida para a cidade de São Paulo entre as décadas de 1970 e 90. O objetivo é o estudo e compreensão da arquitetura contemporânea brasileira através da análise de projetos residenciais de um dos mais importantes escritórios que se destacam na produção atual. Foram identificados e analisados os seus traços característicos através do estudo do partido arquitetônico de cada obra selecionada, o qual leva em consideração as questões da distribuição dos programas juntamente com a estratégia de implantação, as relações dos espaços, a estrutura, as técnicas construtivas e todo o conceito que a obra é fundamentada. O objetivo específico foi a análise dos partidos arquitetônicos das residências selecionadas projetadas por Eduardo de Almeida, por meio de desenhos e diagramas.

A pesquisa se justifica pelo fato de analisar e valorizar a investigação de exemplares nacionais de um arquiteto de grande relevância como Eduardo de Almeida, no sentido de se compreender arquitetura por meio de desenhos e diagramas.

Por meio da investigação por desenhos e diagramas foi possível compreender como o arquiteto organizou o programa de necessidades das residências selecionadas e, portanto analisar seus partidos arquitetônicos.

A análise foi realizada de modo a entender cada projeto individualmente e em relação ao conjunto selecionado.

Em meio à essa produção, na qual os projetos privilegiam grandes estruturas de concreto sem muito acabamento, Eduardo de Almeida se destaca com projetos com um perfeito acabamento industrial, quase em regime artesanal, com detalhes minuciosos nos encontros dos materiais e também como um arquiteto que soube absorver as diferentes linguagens e soluções arquitetônicas.

\section{Resultados e Discussão}

A pesquisa foi realizada a partir de levantamento de bibliografia, leituras, análise por desenhos e imagens. Os projetos foram redesenhados, analisados por meio de desenhos para o estudo do partido arquitetônico. Além disso, foram construídos modelos digitais para análise do projeto. Os projetos analisados são: Residência no Jardim Guedala, São Paulo, 1977; Residência na Cidade Jardim, São Paulo, 1978; Residência no Jardim Paulistano, São Paulo, 1996; Residência no Jardim Paulistano II, São Paulo, 1999.

\section{Conclusões}

Análise gráfica e os modelos digitais se revelaram os melhores meios para analisar, verificar e compreender os partidos dos projetos selecionados. É um processo de leitura ativo dos projetos, que promove um olhar crítico, atento e de uma reflexão contínua. A mesma ferramenta usada para criar, o desenho, é usada para compreender a arquitetura, suas partes e o todo, e importante meio para organizar e comparar as residências analisadas.

\section{Agradecimentos}

Agradeço à minha orientadora Prof Ana M.Tagliari Florio e a PIBIC-SAE pelo incentivo e a oportunidade de pesquisa.

GUERRA, Abílio (org.). Eduardo de Almeida. Arquiteto Brasileiro Contemporâneo. São Paulo: Romano Guerra, 2006.

Iwamizu, Cesar Shundi. Eduardo de Almeida. Reflexões sobre estratégias de projeto e ensino. São Paulo, 2015. 545 p. Tese de doutorado FAUUSP. Orientadora: Helena Parecida Ayoub Silva

MACIEL, Carlos Alberto. Arquitetura, projeto e conceito. Arquitextos, São Paulo, ano 04, n. 043.10, Vitruvius, dez. 2003 <http://www.vitruvius.com.br/revistas/read/arquitextos/04.043/633>.

Florio, Ana Maria Tgliari, Os projetos residenciais não-construídos de Vilanova Artigas em São Paulo. São Paulo, 2012. 417 p. Tese de Doutorado FAUUSP .Orientador: Rafael Antonio Cunha Perrone 